\title{
On cultures and information technology applications in organizations
}

\author{
Pertti Järvinen \\ University of Tampere \\ P.O. Box 607, FIN-33101 Tampere, Finland \\ Phone +358 31 2156777; Fax +358 312156070 \\ Email:pj@cs.uta.fi
}

\begin{abstract}
Some empirical studies concerning usage of new information systems and of general office systems (such as word processing systems) show that all the potential features of those systems have not been used at all. The reason for this is suspected to lie in organizational cultures. There are, however, very few studies on how information technology (IT) applications fit in with an organizational culture. In this paper, firstly, a typology of organizational cultures is presented and, secondly, an analysis is made of how harmonious the fit is between IT applications and a certain cultural type. It is shown that IT applications and organizational cultures mutually affect each other. Advances in IT, together with policy level decisions being made in organizations, may lead to increasingly complex situations. The fit between IT and varieties of organizational culture represents a new challenge for IT design and the IT community.
\end{abstract}

\section{INTRODUCTION}

The recent development of the Internet has brought the global village a bit closer. The so-called global world is most probably not the whole world, but the metaphor has its importance in terms of culture (Berleur, this volume). Global business on the superhighway and its potential implications for the office of the future has been sketched and evaluated (Glasson, 1996) with differing views on whether technical aspects or social ones will dominate.

Organizations today face unprecedented change in their environment. Information technology (IT) continues to be integral to creating products and delivering services, as well as a critical enabler of business strategy execution 
(Henderson and Venkatraman, 1993). It is clear that, even though IT has evolved from its traditional orientation of administrative support toward a more strategic role within an organization, there is still a glaring lack of fundamental frameworks within which to understand the potential of IT for tomorrow's organizations.

The modern resource-based theory of the firm (Conner and Prahalad, 1996) considers the firm as a collection of heterogeneous resources: physical and human resources, knowledge, organizational routines and culture. The latter, the organizational culture spread over the whole organization can form a sustainable competitive advantage.

Quinn et al. (1990) have in the field of management collected models and cultures of management. Some models emphasize either control or flexibility, some models stress the importance of either a firm's internal arrangements or its external relationships. In this paper, the analysis is directed at how a potential or a real IT application fits in with a particular organizational culture. This study will in some sense be more complete and wider than others because Knoll and Jarvenpaa (1994) in their covering review of literature showed that the earlier organizational-IT fit research has mainly considered internal aspects within a stable environment.

Kling and Jewett (1995) in their social analysis of computing systems speak of two dimensions of these systems, which they term: I. Closed/open systems, and II. Rational/natural systems, taken from Scott (1992). Kling and Jewett's dimension of closed/open systems corresponds to the dimension referred to in this paper as 'internal/external', and their 'rational/natural systems' dimension quite closely corresponds to what is called here the dimension of 'control/ flexibility'. Kling and Jewett mainly emphasize the consequences of computing or networking for the work organization and workers, whereas here the emphasis is on the analysis of cultures.

The rest of this paper is structured in the following way: in the section that follows a typology of organizational cultures is selected and presented. Thereafter, a detailed analysis is given of how to make a potential or real IT application fit in with a particular organizational culture. Before the final summarizing discussion, some organizational policy issues are considered.

\section{TYPOLOGY OF ORGANIZATIONAL CULTURES}

In this section, some basic concepts like organizational climate and culture are first defined. Thereafter follows an analysis of some potential frameworks for structuring an evaluation of the IT-organizational cultural fit. The typology chosen identifies four main categories of organizational culture.

The FOCUS-group (1996) reports considerable discussion about the meaning of the words 'climate' and 'culture'. The group prefers the following definition: 'Organizational climate is the collective perception of the relatively stable value orientations in the organization in its entirety, which influence the behaviour of the members regarding the efficient functioning of the organization and which is presented in a descriptive way by the members of the organization'. The construct of organizational culture appeared more recently than organizational climate. In the domain of organizational culture there are two approaches, namely an organization 
is a culture and an organization has a culture. In the first approach, the organization has a culture with symbols, stories, myths which is meaningful to the employees. That is, the way of working together and organizing has a special meaning for the people who work in the organization. This view of the organization excludes cultural typologies, because each culture is considered to be unique.

In the second approach, an organization has a culture besides other organizational variables like structure, leadership, reward systems, etc. Organizational culture is the glue which holds the organization together (Deal and Kennedy, 1982). This approach promotes the study of organizational culture as a system of shared meanings, assumptions, and underlying values (Schein, 1985).

Quinn (1988) has identified an evolution of management models starting from the beginning of this century. He finds four classes of model: the rational goal, the internal process, the human relations, and the open systems models. Each model belongs to one quadrant formed by two dimensions. Does the model emphasize the internal affairs of the organization or its relations to the external environment? Is the organization oriented towards flexibility or towards controlling/maintaining the current situation? Quinn et al. (1990) characterize these models by using the terms market, hierarchy, clan, and adhocracy. They divide each quadrant into two parts, create eight roles, and call the result the competing values framework. These eight roles of managers do not fit in well with the purpose of the present analysis where the emphasis is on cultural types. Therefore, the formulation of organizational cultures made by Smart and St. John (1996) has been selected, and this is summarized in Figure 1.

These four organizational cultures will be considered as ideal types in the Weberian sense and are briefly characterised below.

The clan culture (upper left quadrant in Figure 1) is characterized as having high flexibility, individuality, and spontaneity, as well as internal emphasis, a short-term time frame, and a focus on smoothing activities. In clan cultures the primary leadership style is that of a mentor or facilitator, bonding mechanisms emphasize loyalty and tradition, and the strategic approach focuses on human resources and cohesion.

The hierarchy or bureaucracy culture (bottom left quadrant in Figure 1), like a clan culture, has an internal emphasis, a short-term time frame, and a focus on smoothing activities but differs in its emphasis on stability, control, and predictability. The dominant leadership style is that of the coordinator or organizer, rules and policies are the primary bonding mechanisms, and the strategic emphasis is on permanence and stability.

The adhocracy culture (upper right quadrant in Figure 1), like the clan culture, emphasizes flexibility, individuality, and spontaneity but differs in its emphasis on external positioning, a long-term time frame and achievement-oriented activities. The entrepreneur and innovator leadership styles are prevalent in adhocracy cultures, the bonding mechanisms emphasize innovation and development, and growth and acquisition of new resources constitute the primary strategic emphases.

The market culture (bottom right quadrant in Figure 1) shares an emphasis on external positioning, a long-term time frame, and achievement-oriented activities with the adhocracy culture but differs in its valuing of stability, control, and predictability. The leadership style most compatible with the market culture is that of the producer or hard-driver, while goal attainment provides a bonding 
mechanism, and the strategic emphasis is on competitive actions and achievements.

Figure 1. Typology of organizational cultures

Form: Clan

Leader style: Mentor, facilitator

Bonding: Loyalty, tradition

Strategic emphasis: Human

resources, cohesion

Internal emphasis

Short-term orientation-
Flexibility
Individuality
Spontaneity

Smoothing activities

Form: Hierarchy

Leader style: Coordinator, organizer

Bonding: Rules, policies

Strategic emphasis:

permanence, stability

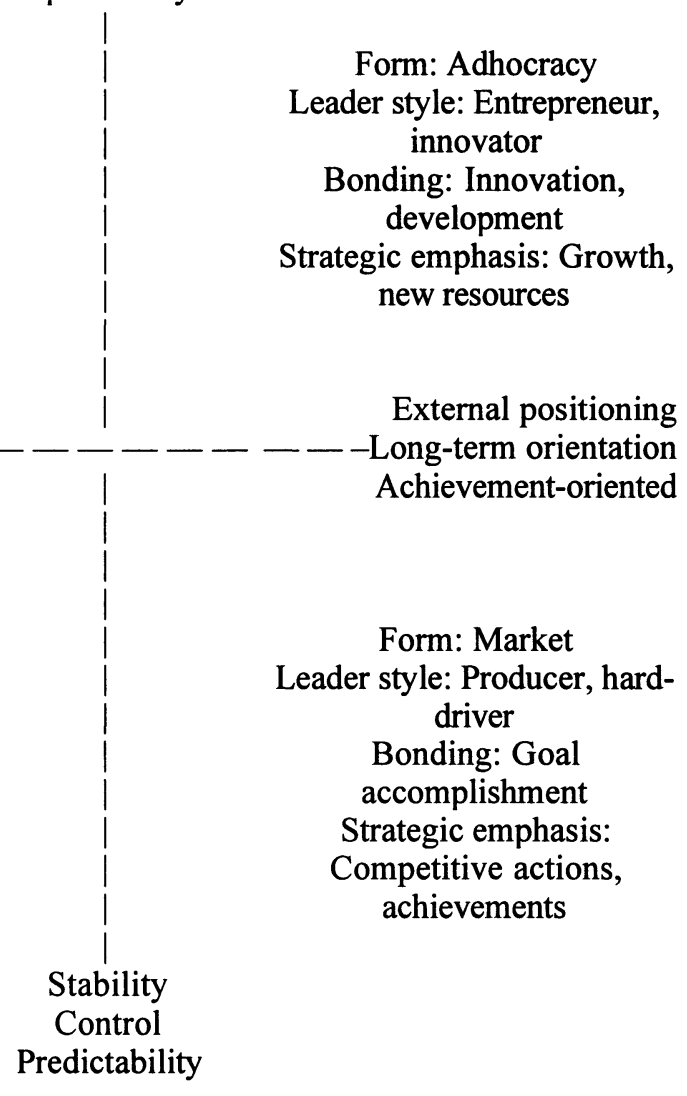

Before using the typology, mention needs to be made concerning democracy, another key concept in this discussion, at the organizational level. In the organizations emphasizing flexibility, their participants share a common interest in the survival of the organization and engage in collective activities to secure this end. It is important to note that organizational democracy will be realized in those organizations emphasizing flexibility.

In the next four sections, our analysis of potential and real relationships between cultural types and IT applications will contain both empirical studies and 
conceptual speculations, i.e., so-called thought experiments. In each section, a cultural type is first characterized together with some features of IT applications supporting this type, and then some cases are described from the literature. General comments and organizational policy issues are considered in a separate section after the detailed analysis.

\section{IT AND HIERARCHY}

An organization oriented towards the individual and towards the control of individual behaviour has a rules-oriented culture. A bureaucratic organization is a prototype. Order, discipline, and systematic work are important. The IT applications developed to support a hierarchical organizational culture contain rules and procedures. A questioning/answering system is a good example where a program controls a dialogue with a user. Our first example below describes how the information systems (IS) development was controlled, and the second example how the new IS can support empowerment.

Orlikowski (1991) has described how a large international consulting firm used a Computer-Aided Systems Engineering (CASE) tool to control the work of systems analysts. The firm hired college graduates and MBAs without any computing experience and trained them with their own methods. The firm reviewed the newer consultants every two years. The new CASE tool was designed to enforce a specific sequence of design activities. The older consultants found that systems development activities with the new CASE tool required less skill than earlier. Somebody else could immediately continue the work performed earlier by another colleague. Orlikowski found that the firm exercised the systemic form of control by a socialization process which comprised a 'significant area of cultural control - control of conduct'. The firm could in real time evaluate and control the current project on the basis of records made by the CASE tool. Hence Kling and Jewett (1995) said that 'this firm's use of the customized CASE tool has some important parallels with Perrolle's (1986) characterization of intellectual assembly line'.

Kling and Jewett (1995) paid attention to Zuboff's (1988) 'informating' concept and its positive application. Zuboff defined her key concepts 'automate' and 'informate' as follows:

"To "automate" is to replace human activity with a machine (computer) which is faster, more reliable, more subject to control etc. The goals of automation have typically been those of cost reduction, efficiency, and productivity. Automation means applying technology in ways that increase the self acting and self regulating capacities of machine systems, thus minimising human intervention. Intelligent technology can be used to automate, but even as this occurs, the technology has the capacity to translate those automated activities into data and to display those data. Information technology symbolically renders processes, objects, behaviours and events such that they become visible, knowable and sharable in a new way. The word Zuboff coined to describe this second function is "informate".'

Zuboff (1988) reported an intriguing case of informating in her study of an expense tracking system in a paper plant. Operators in the plant learned about the 
costs of making paper from a computerized subsystem that had been added to their equipment controlling the paper-making process. By experimenting with their equipment they were able to reduce the costs of producing paper significantly, because the new system informed them about the costs of chemicals and other ingredients.

Kling and Jewett (1995) saw some features of the human relations school or the clan culture in Zuboff's findings, because the operators felt that they owned the system and it empowered them. This might be a special case. In general, the informating concept may be applicable in cases where the object of work is material or human (not data) and the new computing system makes the object more visible. An application of IT may then, as in Zuboff's case, cause some emergent organizational changes.

\section{IT AND CLAN}

An organization oriented towards people and with internally oriented flexibility has a supportive, clan culture. In this cultural type the human being takes a central position. People trust each other, help each other and feel at home in the organization. In an organization following the clan culture, the IT is applied by building an infrastructure to support cooperation and sharing knowledge. Our example concerns groupware in an IT firm. One department was established to help customers to solve their problems with the IT products delivered by the firm.

Orlikowski (1995) examined the use of a groupware technology (Lotus Notes) in the context of customer support to understand how the technology was used to enable organizational changes over time. Building on its successful implementation of the groupware technology two years earlier, the customer support department brought about many organizational changes that altered the nature and distribution of work, forms of collaboration, utilization and dissemination of knowledge. Some of the organizational changes were planned and some were emergent; use of the new electronic mechanism for collaboration led to an interesting emergent change in the department: it shifted the form of collaboration from being primarily reactive to being primarily proactive. Because all specialists had access to the database of customer calls being worked on in the department, they browsed through each others' calls to see which ones they could help with. Rather than waiting to be asked if they had solutions to particular problems (reactive collaboration), they actively sought problems that they had solutions for (proactive collaboration).

Silver et al. (1995) judged that (1) 'in an organization that values individuality over teamwork, groupware systems - especially those that operate with anonymity - may fail to achieve their desired consequences of promoting productive collaborative work. On the other hand, when coupled with other measures, such a groupware system might be used as part of a conscious effort to make the corporate culture more team oriented'. Thus it is very important to note that the relationship between organizational culture and IT systems might work in two opposite directions. 


\section{IT AND MARKET}

An organization oriented towards the goals of the organization and towards the control of the means to reach these goals has a market culture. Everyone works in the same customer-oriented direction. Productivity is emphasized. People who contribute to the realization of goals are rewarded. The IT applications can be built to help managers to control the optimal use of resources. Our example concerns the introduction of the IT package to the consulting company whose market culture was in conflict with the idea behind the package.

Orlikowski (1992) explored the introduction of groupware into an organization to understand the changes in the work practices and social interaction facilitated by the technology. The chief information officer of a large international consulting firm carefully chose a new groupware package (Lotus Notes) to help the firm to manage its expertise and transform its practice. Results suggested that people's mental models and the organization's structure and culture significantly influenced how the groupware was implemented and used. Specifically, in the absence of mental models that stressed its collaborative nature, groupware was interpreted in terms of familiar, personal, stand-alone technologies such as spreadsheets. Further, the culture and structure of the firm provided few incentives or norms for cooperating or sharing expertise, for example, the consultants' incentive structure was based on having 'billable time' from clients for each of their activities. The firm's managers failed to modify this incentive structure. The consultants had no way to bill the significant amount of time (15-30 hours) taken to learn to use the new software or the time spent writing case reports that might help another consultant.

\section{IT AND ADHOCRACY}

The adhocracy culture emphasizes organizational flexibility, and relationships between the firm and its environment. The specialists in such a firm are oriented towards searching for all kinds of new things. The following elements are typical of an adhocracy culture: growth, taking risks, creativity, competition, individual responsibility, being open to scientific findings, and following courses to improve knowledge and skills. The example considered below is a hypothetical case, a sketch of an adhocracy type firm and how its arrangements can be supported by IT.

Boland and Tenkasi (1995) claimed that knowledge-intensive firms are composed of multiple communities with specialized expertise, and are often characterized by lateral rather than hierarchical organizational forms. Producing knowledge to create innovative products and processes in such firms requires the ability to have strong perspectives within community, as well as the ability to take the perspective of another into account.

Boland and Tenkasi presented models of language, communication, and cognition that can assist in the design of electronic communication systems for perspective making and perspective taking. By appreciating how communication is both like a language game played in a local community and also like a transmission of messages through a channel, and by appreciating how cognition includes a capacity to narrativize our experience as well as a capacity to process information, Boland and Tenkasi identified some guidelines for designing 
electronic communication systems to support knowledge work. The communication systems they proposed emphasize that narratives can help construct strong perspectives within a community of knowing, and that reflecting on and representing that perspective can create boundary objects which allow for perspective taking between communities.

Boland and Tenkasi also presented a 'plausible, but admittedly utopian form of a knowledge intensive firm'. They structured their representation by considering it from the technological, organizational and cultural aspects. Technologically, they expected that computing, imaging, and communication devices have become ubiquitous. The information environment in this hypothetical firm is a seamless integration of multimedia devices for collection, storage, processing, and display. The organization is replete with systems based on the channel model and language games model. Once certain kinds of knowledge are established and the perspective of a community of knowing becomes mature, the decision routines are embedded in project management and other kinds of software, although such decision premises are always subject to question and revision. Graphics, texts, models, audio, and video applications are all radically tailorable to a user's needs. Hyperlinks from an element in any one application to elements in any other application are fully supported, making contextually rich, complexly layered, representations the norm. Groupware is highly developed, with multimedia meetings, and discussion groups in a wide variety of issue forums. A sophisticated vocabulary of electronic forums for initiating, replying or commenting on decision models and discussion topics has emerged through an open process of structuration (Giddens, 1979).

According to Boland and Tenkasi, organizationally, the firm is characterized by a critical density of interdependent knowledge communities. The organization uses lateral teams extensively in which the vertical authority structure plays a muted role while the principle of value-adding activities of knowledge creation and knowledge application are carried out in a changing 'mosaic' of lateral project teams.

Culturally, the idea that doing work in a knowledge-intensive firm means perspective making and perspective taking in communities of knowing has taken hold and has shaped both individual and group identities. Individuals have a reflexive awareness of their ways of processing information as well as their narrative modes of cognition. Members of the firm enter into and make readings of communication episodes with an open awareness of the hermeneutic circle in which they tack back and forth from an interpretation of the larger context of a perspective to an interpretation of the detailed elements of the message at hand. They realize that debate is a win-lose polarizing strategy that rarely results in true synthesis or creative insights. Dialogue, in contrast, is mutually reinforcing, working together through language. It is a realization that we can assume a perspective taking orientation and benefit from opening ourselves to the horizon of another.

Within the organizational, cultural, and technological environment sketched by Boland and Tenkasi, communities of knowing are using advanced groupware facilities to conduct meetings, construct multi-author documents, and coordinate their promises and deadlines, all with the capability of accessing data and knowledge through a worldwide network of knowledge repositories. 
Since groups form and reform in a knowledge-intensive firm employing a lateral organization, Boland and Tenkasi proposed five classes of electronic communication forums for enhancing perspective making and perspective taking: 1 . Task narrative forums, 2. Knowledge representation forums, 3. Interpretative reading forums, 4 . Theory building forums, and 5. Intelligent agent forums.

\section{GENERAL COMMENTS AND SOME ORGANIZATIONAL POLICY ISSUES}

First, some comment is given on the analyses in the previous four sections, and then organizational policy issues are considered such as electronic mail, end user computing, and outsourcing. The few examples above show that cultural type can have an influence on the usage of a certain IT applications. If the latter does not fit in with the organizational culture of a firm, some problems will appear. The examples also show that the IT applications which do fit in very well with the cultural type can trigger positive processes not planned at all.

Electronic mail and a computer network in an organization gives employees the chance to communicate freely with each other and to form news and discussion groups. The employer exercizing hierarchical control may not like to see that some clan subcultures will emerge in the network that are difficult to control. Silver et al. (1995) estimated that, given the information sharing and communication capabilities of IT, traditional organizational hierarchies are giving way to adhocracies and networked organizations.

Kumar and van Dissel (1996) recently studied how to manage conflicts and cooperation in interorganizational systems. The highest form of interdependence between interorganizational units is the reciprocal dependency where units feed their work back and forth among themselves, that is, each receives input from and provides output to others, often interactively. The authors claim that group technologies may diminish risks of socio-political conflicts but, at the same moment, they pay attention to another aspect. They evaluate that group technologies, at their current level of evolution, at best provide a value-neutral platform for enabling such interorganizational systems. At worst, which is usually the case, they incorporate the value judgements of the culture in which they were conceived and developed.

End user computing, in contrast to corporate computing, may contain the independent use of spreadsheets, graphics, word processing, queries and report generation, and desktop publishing (McLean et al., 1993). Capable employees can build their own IT applications which may cause some overlapping and conflicting effects with corporate computing. These surely are not desired in the organizations emphasizing control in their culture.

McFarlan and Nolan (1995) recommended that the outsourcing contract of an organization with an IT firm should last at least 10 years. In a turbulent world such a contract cannot then be restrictive. For the IT firm it is profitable to install similar IT applications into many organizations. We can now imagine what would happen if the IT firm were to develop its applications which previously supported a particular cultural type, such as a hierarchy, in such a direction that they would 
support another cultural type say, for example, a clan. Some control concerning the selected cultural type in the organization will be moved to another firm.

We can conclude that some technical advances in IT like groupware and local area networks, and some organizational policy issues like end user computing and outsourcing, can in some cases create problems with sustaining a selected cultural type.

\section{DISCUSSION}

The analysis of the four cultural types and consideration of wider issues shows that the question of how a potential or real IT application fits in with an organizational culture can be solved rather easily at the IT application level. There are IS supporting each cultural type. The advances in IT technology and some political issues clearly increase the complexity of this problem area. Managers must be also aware of cultural aspects when they are making decisions on the development of a new information system, on purchasing new IT technology for the organization, and on making contracts with an IT firm.

The above analysis was widely based on examples in order that the reader could make his or her own judgements when following the argument. The purpose was in this way to support intersubjectivity.

The reengineering of organizations has recently been connected with the new opportunities offered by IT. At the same time a more horizontal division of labour is emphasized, but as Barley (1996) wrote 'hierarchical practices and ideologies have a way of reemerging even when managers are sincere about adopting more collaborative practices'. The most critical inference to be drawn from Barley's ethnographic study of technicians' work was: 'The most serious barriers to adapting successfully to a changing world of work are likely to be cultural, ... if technicians are at all typical of what a significant proportion of work will be like in a post-industrial economy, the difficulties of reengineering firms will pale before the cultural and institutional changes that we may need to contemplate'.

In the longitudinal development program (Harkness et al., 1996), the Bose leaders very early recognized that process improvement techniques (such as Business Process Reengineering and Total Quality Management) and the existing organizational culture needed to be synthesized into a pattern of work that leveraged the strengths of both.

One aspect still needs to be taken into consideration, namely the possible combinations of cultural types. There are some ideas to support such a view (Quinn et al., 1990) that, on the one hand, the hierarchy and the adhocracy and, on the other hand, the clan and the market are complementary rather than mutually exclusive. In the discussion of adhocracy above, reference was made to Boland and Tenkasi (1995) who stressed that 'individuals have a reflexive awareness of their ways to process information as well as their narrative modes of cognition', that is, the researchers recommend the use of two complementary models. Nonaka (1994) also recommended a similar arrangement called a 'hypertext organization' for creating knowledge in an organization. The core feature of the hypertext organization is the ability to switch between the various contexts to accommodate changing requirements from situations both inside and outside the organization. 
Those contexts can be situations such as the acquisition, generation, exploitation, and accumulation of knowledge. Each context has, according to Nonaka, a distinctive way of organizing its knowledge creation activities. Heterarchical selforganizing activities are indispensable for generating new knowledge as well as for acquiring 'deep' knowledge through intensive, focused search. On the other hand, a hierarchical division of labour is more efficient and effective for implementation, exploitation, and accumulation of new knowledge as well as acquisition of diverse information through extensive, unfocused search.

The complementary use of the hierarchy and the adhocracy, on the one hand, and the clan and the market, on the other hand, means a new challenge for the IT community. Thus, for the same firm, where there is an emphasis on efficiency, information systems need to be built that support those processes and, where creativity is emphasized, other information systems need to be designed that support these processes.

\section{REFERENCES}

Barley S.R. (1996), Technicians in the workplace: Ethnographic evidence for bringing work into organization studies. Administrative Science Quarterly 41, (3), 404-441.

Berleur J. (this volume), Culture and democracy revisited in the global information society. Summary of a position paper.

Boland R.J. and R.V. Tenkasi (1995), Perspective making and perspective taking in communities of knowing. Organization Science 6, (4), 350-372.

Bunge M. (1967), Scientific Research I. The Search for System. Springer-Verlag, Berlin.

Conner K.R. and C.K. Prahalad (1996), A resource-based theory of the firm: Knowledge versus opportunism,. Organization Science 7, (5), 477-501.

Deal T.E. and A.A. Kennedy (1982), Corporate cultures: The rights and rituals of corporate life, Addison-Wesley, Reading.

FOCUS-group (1996), First organizational cultural unified search, Vlaams Instituut voor Zelfstandig Ondernemen, Limburg, manuscript.

Giddens A. (1979), Central problems in social theory. MacMillan, London.

Glasson B. (1996), Global business on the superhighway: Implications for the office of future, In Terashima and Altman (Eds.), Advanced IT tools. Chapman \& Hall, London, 117-128.

Harkness W.L., W.J. Kettinger and A.H. Segars (1996), Sustaining process improvement and innovation in the information services function: Lessons learned at the Bose corporation. MIS Quarterly 20, (3), 349-368.

Henderson J.C. and N. Venktraman (1993), Strategic alignment: Leveraging information technology for transforming organizations. IBM Systems Journal 32, (1), 4-16.

Kling R. and T. Jewett (1995), The social design of worklife with computers and networks: An open natural systems perspective. In Yovits (Ed.), Advances in Computers No 39, Academic Press, Orlando, 239-293.

Knoll K. and S.L. Jarvenpaa (1994), Information technology alignment or 'fit' in highly turbulent environments: The concept of flexibility. Proceedings of the 1994 ACM SIGCPR Conference, March 1994, pp. 1-14.

Kumar K. and H.G. van Dissel (1996), Sustainable collaboration: Managing conflict and cooperation in interorganizational systems. MIS Quarterly 20, (3), 279-300.

McFarlan F.W. and R.L. Nolan (1995), How to manage an IT outsourcing alliance. Sloan Management Review 36, (2), 9-23.

McLean E.R., L.A. Kappelman and J.P. Thompson (1993), Converging end-user and corporate computing, Communications ACM 36, (12), 79-92.

Nonaka, I. (1994), A Dynamic Theory of Organizational Knowledge Creation. Organization Science 5 (2), 14-37. 
Orlikowski W.J. (1991), Integrated information environment or matrix of control? The contradictory implications of information technology. Accounting, Management \& Information Technology 1 (1), 9-42.

Orlikowski W.J. (1992), Learning from Notes: Organizational issues in groupware implementation, In Proceedings of CSCW'92, ACM, New York, 362-369.

Orlikowski W.J. (1995), Evolving with Notes: Organizational change around groupware technology, URL: http://ccs.mit.edu/CCSWP186.html (June 1995).

Perrolle J. (1986), Intellectual assembly lines: The rationalization of managerial, professional, and technical work. Computers and the Social Sciences 2, (3), 111-122 (also in Dunlop and Kling, 1991, Computerization and controversy: Value conflicts and social choices. Academic Press, San Diego, 221-235).

Quinn R.E. (1988), Beyond rational management. Jossey-Bass, San Francisco.

Quinn R.E., S.R. Faerman, M.P. Thompson and M.R. McGrath (1990), Becoming master manager - A competency framework. Wiley, New York.

Schein E.H. (1985), Organizational culture and leadership. Jossey-Bass, San Francisco.

Scott W.R. (1992), Organizations: Rational, natural and open systems. Prentice-Hall, Englewood Cliffs.

Silver M.S., M.L. Markus and C.M. Beath (1995), The information technology interaction model: A foundation for the MBA core course. MIS Quarterly 19, (3), 361-390.

Smart J.C. and E.P. St. John (1996), Organizational culture and effectiveness in higher education: A test of the 'Culture Type' and 'Strong Culture' hypotheses. Educational Evaluation and Policy Analysis 18, (3), 219-241.

Zuboff S. (1988), In the age of the smart machine: The future of work and power. Basic Books, New York. 